\title{
Health Benefits of Fruits and Vegetables ${ }^{1}$
}

\author{
Joanne L. Slavin ${ }^{2 *}$ and Beate Lloyd ${ }^{3}$ \\ ${ }^{2}$ Department of Food Science and Nutrition, University of Minnesota, St. Paul, MN; and ${ }^{3}$ PepsiCo Nutrition, Global Research and Development, \\ PepsiCo, Valhalla, NY
}

\section{ABSTRACT}

Fruits and vegetables are universally promoted as healthy. The Dietary Guidelines for Americans 2010 recommend you make one-half of your plate fruits and vegetables. Myplate.gov also supports that one-half the plate should be fruits and vegetables. Fruits and vegetables include a diverse group of plant foods that vary greatly in content of energy and nutrients. Additionally, fruits and vegetables supply dietary fiber, and fiber intake is linked to lower incidence of cardiovascular disease and obesity. Fruits and vegetables also supply vitamins and minerals to the diet and are sources of phytochemicals that function as antioxidants, phytoestrogens, and antiinflammatory agents and through other protective mechanisms. In this review, we describe the existing dietary guidance on intake of fruits and vegetables. We also review attempts to characterize fruits and vegetables into groups based on similar chemical structures and functions. Differences among fruits and vegetables in nutrient composition are detailed. We summarize the epidemiological and clinical studies on the health benefits of fruits and vegetables. Finally, we discuss the role of fiber in fruits and vegetables in disease prevention. Adv. Nutr. 3: 506-516, 2012.

\section{Introduction}

Diets high in fruits and vegetables are widely recommended for their health-promoting properties. Fruits and vegetables have historically held a place in dietary guidance because of their concentrations of vitamins, especially vitamins $\mathrm{C}$ and A; minerals, especially electrolytes; and more recently phytochemicals, especially antioxidants. Additionally, fruits and vegetables are recommended as a source of dietary fiber.

Most countries have dietary recommendations that include fruits and vegetables. Table 1 summarizes the recommendations for 3 countries: Canada (1), the United Kingdom (2), and the United States (3). Although dietary recommendations have many similarities, different countries choose different strategies to separate fruits and vegetables into groups. Orange fruits and vegetables are often high in carotenoids and are placed in a separate category. Yet many dark green vegetables (i.e., spinach) are also high in carotenoids. Dividing fruit and vegetables into color categories makes sense for menu planning but does not correspond with nutrient content.

Certain fruits and vegetables are rich sources of vitamin $\mathrm{C}$, but these rich sources (citrus fruits, strawberries, green peppers, white potatoes) are spread over many fruit and vegetable categories. Other fruits and vegetables, including

\footnotetext{
${ }^{1}$ Author disclosures: J. L. Slavin and B. Lloyd, no conflicts of interest.

*To whom correspondence should be addressed. E-mail: jslavin@umn.edu.
}

avocado, corn, potatoes, and dried beans, are rich in starch, whereas sweet potatoes are mostly sucrose, not starch. Fruits (except bananas) and dark green vegetables contain little or no starch. Often, dietary guidance rules place fruit juices and potatoes in separate categories, because of dietary directives to eat whole fruits and minimize consumption of foods high in fat and sodium, i.e., French fries. The vegetable and fruit categories in the 2010 Dietary Guidelines for Americans (3) are listed in Table 2. These categories are important, because they drive policy for programs such as school lunch and other supplemental feeding programs.

According to the Dietary Guidelines for Americans 2010, nutrients of concern in the American diet include potassium, dietary fiber, calcium, and vitamin D. Energy density and intake are also important issues in the American diet. Fruits and vegetables are generally low in energy density and often are good sources of fiber and potassium, but the nutritional contribution of standard servings of fruits and vegetables varies widely (4). The content of phytochemicals, such as polyphenolics, also varies greatly (5) and is not listed in nutrient databases.

We have provided a nutritional comparison of the 10 most commonly consumed fruits and vegetables (Table 3 ). It should be noted that fruits and vegetables are often not consumed in the raw form but may be cooked, fried, or combined with other ingredients prior to consumption. Thus, whereas a boiled potato is a nutrient-dense food, a fried potato may contribute a substantial amount of fat 
Table 1 National guide analyses: Canada, United Kingdom, United States

\begin{tabular}{|c|c|c|c|}
\hline & Canada & United Kingdom & United States \\
\hline Name & Canada's Food Guide & Eatwell Plate & My Plate \\
\hline Agency & Health Canada & $\begin{array}{l}\text { Food Standards Agency/National } \\
\text { Health Service }\end{array}$ & USDA \\
\hline Number of food categories & 4 & 5 & 6 \\
\hline Key messages & $\begin{array}{l}\text { 1. Eat at least one dark green } \\
\text { and one orange vegetable } \\
\text { each day. } \\
\text { 2. Enjoy vegetables and fruit } \\
\text { prepared with little or no } \\
\text { added fat, sugar, or salt. } \\
\text { 3. Have vegetables and fruit } \\
\text { more often than juice. }\end{array}$ & $\begin{array}{l}\text { Try to eat plenty of fruits } \\
\text { and vegetables }\end{array}$ & $\begin{array}{l}\text { Increase vegetable and fruit intake. } \\
\text { Eat a variety of vegetables, } \\
\text { especially dark-green, red, and } \\
\text { orange vegetables and beans } \\
\text { and peas. }\end{array}$ \\
\hline Units & $\begin{array}{l}\text { Servings, cups } \\
1 \text { cup }=250 \mathrm{~mL}\end{array}$ & Portions $(1$ portion $=80 \mathrm{~g})$ & $\begin{array}{l}\text { Servings, cups } 1 \text { cup raw leafy } \\
\text { vegetables }=84 \mathrm{~g}\end{array}$ \\
\hline Vegetable & - & & 3 cups/d, $2400 \mathrm{kcal}$ \\
\hline Fruit & - & & $2 \mathrm{cups} / \mathrm{d}, 2400 \mathrm{kcal}$ \\
\hline Vegetable and fruit & $\begin{array}{l}\text { 7-8 servings (adult) } \\
4-6 \text { (children) }\end{array}$ & 5 portions/d $(400 \mathrm{~g} / \mathrm{d})$ & - \\
\hline Vegetable & $\begin{array}{l}\text { One serving is: 1) } 1 \text { cup } \\
\text { ( } 250 \mathrm{~mL} \text { ) of raw green leafy } \\
\text { vegetables, such as salad, } \\
\text { spinach, collards; } 2) 1 / 2 \\
\text { cup (125 mL) of other } \\
\text { vegetables steamed, cooked, } \\
\text { or raw, e.g., broccoli, snow } \\
\text { peas, carrots; } 3 \text { ) } 1 / 2 \text { cup } \\
100 \% \text { vegetable juice }\end{array}$ & $\begin{array}{l}\text { A portion is } 80 \mathrm{~g} \text { of these: } \\
\text { 1) } 3 \text { heaped tablespoons of } \\
\text { vegetables (raw, cooked, frozen, } \\
\text { tinned); 2) } 3 \text { heaped tablespoons } \\
\text { of beans and pulses (beans } \\
\text { and pulses count a maximum of } \\
1 \text { portion/d); and 3) a dessert } \\
\text { bowl of salad }\end{array}$ & $\begin{array}{l}1 \text { cup green salad; } 1 \text { baked potato; } \\
1 / 2 \text { cup cooked broccoli; } 1 / 2 \text { cup } \\
\text { serving of other vegetable; } 1 / 2 \text { cup } \\
\text { tomato juice }\end{array}$ \\
\hline Fruit & $\begin{array}{l}\text { One serving is: 1) } 1 \text { piece of } \\
\text { fruit (e.g., apple, pear, } \\
\text { banana); 2) } 1 / 2 \text { cup fruit, } \\
\text { e.g., melons, cantaloupe; } \\
\text { 3) } 1 / 2 \text { cup fruit juice }\end{array}$ & $\begin{array}{l}\text { A portion is } 80 \mathrm{~g} \text { or any of these: } \\
\text { 1) } 1 \text { apple, banana, pear, orange, or } \\
\text { other similar-size fruit; } 2 \text { ) } 3 \text { heaped } \\
\text { tablespoons of fruit salad (fresh or } \\
\text { tinned in fruit juice) or stewed fruit; } 3 \text { ) } \\
1 \text { handful of grapes, cherries, or } \\
\text { berries; } 4 \text { ) a glass ( } 150 \mathrm{~mL} \text { ) of fruit } \\
\text { juice (counts as a maximum of } 1 \\
\text { portion/d) }\end{array}$ & $\begin{array}{l}1 / 2 \text { cup fresh fruit; } 1 \text { medium } \\
\text { size fruit; } 1 / 2 \text { cup fruit juice }\end{array}$ \\
\hline Juice & $100 \%, 1 / 2$ cup & $\begin{array}{l}1 \text { glass }(150 \mathrm{~mL}) \text { of fruit juice counts } \\
\text { as } 1 \text { portion, but juice can only } \\
\text { count a maximum of } 1 \text { portion/d }\end{array}$ & $\begin{array}{l}\text { 100\% fruit juice. } 1 \text { cup. } \\
\text { No limits }\end{array}$ \\
\hline Categories & $\begin{array}{l}\text { 1. Dark green } \\
\text { 2. Orange }\end{array}$ & - & $\begin{array}{l}\text { 1) Dark green; 2) red/orange; } \\
\text { 3) beans/peas; 4) starchy; } \\
\text { 5) other vegetables }\end{array}$ \\
\hline Potatoes included? & Yes & $\begin{array}{l}\text { No. Potatoes not included (considered } \\
\text { starchy food) }\end{array}$ & Yes \\
\hline Legumes included? & Yes & $\begin{array}{l}\text { Beans and pulses count only } 1 \\
\text { portion/d, no matter how many } \\
\text { one eats }\end{array}$ & $\begin{array}{l}\text { Yes (protein category as well), } \\
\text { but should be counted in } \\
\text { only one category }\end{array}$ \\
\hline Intake estimates & $\begin{array}{l}5.16 \text { servings (Stat Canada, } \\
\text { 2004) }\end{array}$ & Men: 3.5 portions; women: 3.8 portions & 4.7 servings (NHANES 1999-2000) \\
\hline
\end{tabular}

and sodium to the diet. Fiber concentrations range from 0.6 to $5.1 \mathrm{~g} /$ serving and potassium concentrations range from 76 to $468 \mathrm{mg} /$ serving (Table 3 ). Bananas and potatoes, although technically belonging to different families, have strikingly similar compositions for energy, fiber, and potassium per standard serving. A standard serving of iceberg lettuce contains $8 \mathrm{kcal}$, whereas a potato contains $144 \mathrm{kcal}$ and a banana $105 \mathrm{kcal}$. Of course, iceberg lettuce is seldom eaten alone.

Most estimates of fruit and vegetable consumption are limited by disagreement on what constitutes a serving of a fruit or vegetable. Mean fruit and vegetable intakes (servings/d) are 5.16 servings (Canada), 3.5 portions (men); 3.8 portions (women) (UK) and 4.7 servings (US) (Table 1). Marriott et al. (6) examined intake of carbohydrates, including dietary fiber, in the NHANES data set. Dietary fiber intake was particularly low in their analysis. With the exception of older women ( $\geq 51 \mathrm{y}$ ), only $0-5 \%$ of individuals in all other life stage groups had fiber intakes meeting or exceeding the Adequate Intake $(\mathrm{AI})^{4}$. Common serving sizes of fruits and vegetables contain 1-5 g of fiber. Most

\footnotetext{
${ }^{4}$ Abbreviations used: Al, Adequate Intake; CHD, coronary heart disease; CVD, cardiovascular disease; IOM, Institute of Medicine; TDF, total dietary fiber.
} 
Table 2 USDA Food Patterns: food groups and subgroups

\begin{tabular}{|c|c|}
\hline $\begin{array}{l}\text { Food } \\
\text { group }\end{array}$ & Subgroup and examples \\
\hline \multirow[t]{5}{*}{ Vegetables } & $\begin{array}{l}\text { Dark green vegetables: all fresh, frozen, and canned dark } \\
\text { green leafy vegetables and broccoli, cooked or raw } \\
\text { (broccoli, spinach, romaine, collard, turnip, and mustard } \\
\text { greens) }\end{array}$ \\
\hline & $\begin{array}{l}\text { Red and orange vegetables: all fresh, frozen, and canned } \\
\text { red and orange vegetables, cooked or raw (tomatoes, } \\
\text { red peppers, carrots, sweet potatoes, winter squash, } \\
\text { pumpkin) }\end{array}$ \\
\hline & $\begin{array}{l}\text { Beans and peas: all cooked and canned beans and peas } \\
\text { (kidney beans, lentils, chickpeas, and pinto beans). Does } \\
\text { not include green beans or green peas. }\end{array}$ \\
\hline & $\begin{array}{l}\text { Starchy vegetables: all fresh, frozen, and canned starchy } \\
\text { vegetables (white potatoes, corn, green peas) }\end{array}$ \\
\hline & $\begin{array}{l}\text { Other vegetables: all fresh, frozen, and canned other } \\
\text { vegetables (iceberg lettuce, green beans, onions) }\end{array}$ \\
\hline Fruit & $\begin{array}{l}\text { All fresh, frozen, canned, and dried fruits and fruit juices } \\
\text { (oranges and orange juice, apples and apple juice, } \\
\text { bananas, grapes, melons, berries, and raisins) }\end{array}$ \\
\hline
\end{tabular}

of the fiber in vegetables and fruits is insoluble fiber, except for citrus fruits (Table 3).

\section{Current state of knowledge}

The importance of fiber for the normal function of the digestive system has been long appreciated. Hippocrates is quoted as stating that "whole meal bread makes larger feces than refined bread." In the early 1970s, Burkitt and Trowell (7) published widely on the "fiber hypothesis," stating that higher fiber intakes protect against a wide range of Western diseases. Traditionally, fiber was measured as "crude fiber," which includes only the most resistant fibers consumed. As the scientific support for a role for resistant carbohydrates not captured by the crude fiber method such as pectin, glucans, and oligosaccharides was published, additional analytical methods to measure more carbohydrates resistant to digestion and absorption were needed. Accepted analytical methods to determine dietary fiber were then developed, especially because fiber was included on the Nutrition Facts panel. The Nutrition Labeling and Education Act (1990) required that all packaged foods include the Nutrition Facts panel. Nutrition Facts must include total dietary fiber (TDF); insoluble and soluble fiber also may be listed but are not required unless claims are made.

Besides food manufacturers, epidemiologists, scientists, and dietitians need data on the fiber content of foods (8). Yet attempts to define and standardize methods to measure dietary fiber remain contentious. Dietary fiber is essentially the undigested carbohydrates in the diet (9). These carbohydrates may be fermented in the large intestine, although some resistant fibers, such as purified cellulose, escape any fermentation, whereas other fibers, such as inulin or pectin, are completed broken down by bacteria in the colon.

Most analytical schemes to measure dietary fiber are chemical and enzymatic extraction procedures. The TDF method, or Prosky Method, has become the standard method for the measurement of dietary fiber in the United States. Because the TDF method does not isolate all undigested carbohydrates, especially short-chain oligosaccharides, other methods have been developed and accepted to quantitate these compounds.

Determining the solubility of fiber was an attempt to relate physiological effects to chemical types of fiber (9). Soluble fibers were considered to have beneficial effects on serum lipids and insoluble fibers were linked with laxation benefits. This division of soluble and insoluble fiber is still used in nutrition labeling. However, despite these commonly used generalizations, scientific evidence supporting that soluble fibers lower cholesterol and insoluble fibers increase stool weight is inconsistent. Many fiber sources are mostly soluble but still enlarge stool weight, such as oat bran and psyllium. Also, soluble fibers such as inulin do not lower blood lipids. Most fruits and vegetables are concentrated in insoluble fiber, not soluble fiber (Table 3). Exceptions to this generalization include cooked potatoes, oranges, and grapefruit. The USDA Nutrient Database includes only total fiber; there are no official databases that include soluble and insoluble fiber. Lists of content of total, insoluble, and soluble fibers are compilations of data from the USDA, the published literature, and estimated values (10). Often, the values for soluble and insoluble fiber do not add to total fiber or the values for soluble fiber were estimated by subtracting a literature value for insoluble fiber

Table $3 \mathrm{kcal}, \mathrm{TDF}, \mathrm{IDF}$, and SDF and potassium in the top 10 consumed vegetables and fruits in standard servings listed or NLEA serving sizes ${ }^{1}$

\begin{tabular}{|c|c|c|c|c|c|c|}
\hline $\begin{array}{l}\text { Common } \\
\text { fruit/vegetable }\end{array}$ & Serving & kcal & TDF & IDF & SDF & Potassium \\
\hline & & & & $G$ & & $m g$ \\
\hline Potato, boiled & $1 \mathrm{med}, 167 \mathrm{~g}$ & 144 & 3.0 & 1.6 & 1.4 & 348 \\
\hline Iceberg lettuce & $1 \mathrm{cup}, 57 \mathrm{~g}$ & 8 & 0.7 & 0.6 & 0.1 & 80 \\
\hline Tomato & NLEA, $148 \mathrm{~g}$ & 27 & 1.8 & 1.6 & 0.2 & 351 \\
\hline Onion & NLEA, $148 \mathrm{~g}$ & 47 & 1.3 & 0.8 & 0.5 & 176 \\
\hline Carrot & NLEA, $85 \mathrm{~g}$ & 30 & 2.5 & 2.1 & 0.4 & 201 \\
\hline Celery & NLEA, $110 \mathrm{~g}$ & 18 & 1.8 & 1.7 & 0.1 & 286 \\
\hline Sweet corn & 1 ear, $77 \mathrm{~g}$ & 74 & 1.8 & 1.7 & 0.1 & 168 \\
\hline Broccoli & NLEA, $148 \mathrm{~g}$ & 50 & 3.8 & 3.0 & 0.8 & 468 \\
\hline Green cabbage & 1 cup, $89 \mathrm{~g}$ & 22 & 2.2 & 1.7 & 0.1 & 151 \\
\hline Cucumber, with peel & 1 cup, slices & 16 & 0.6 & 0.5 & 0.1 & 152 \\
\hline Banana & $1 \mathrm{med}, 118 \mathrm{~g}$ & 105 & 3.1 & 2.1 & 1.0 & 422 \\
\hline Apple with skin & $1 \mathrm{med}, 182 \mathrm{~g}$ & 95 & 4.4 & 3.1 & 1.3 & 195 \\
\hline Watermelon & NLEA, $280 \mathrm{~g}$ & 84 & 1.1 & 0.8 & 0.3 & 314 \\
\hline Orange & NLEA, $154 \mathrm{~g}$ & 75 & 3.4 & 1.4 & 2.0 & 256 \\
\hline Cantaloupe & NLEA, $134 \mathrm{~g}$ & 46 & 1.2 & 0.9 & 0.3 & 358 \\
\hline Green grapes & NLEA, $126 \mathrm{~g}$ & 87 & 1.1 & 0.6 & 0.5 & 241 \\
\hline Grapefruit & NLEA, $154 \mathrm{~g}$ & 65 & 2.5 & 0.9 & 1.6 & 208 \\
\hline Strawberry & NLEA, $147 \mathrm{~g}$ & 47 & 2.9 & 2.2 & 0.7 & 225 \\
\hline Peach & NLEA, $147 \mathrm{~g}$ & 57 & 2.2 & 1.2 & 1.0 & 279 \\
\hline Pear & NLEA, $166 \mathrm{~g}$ & 96 & 5.1 & 3.6 & 1.5 & 198 \\
\hline
\end{tabular}

Data on kcal, TDF, and potassium from USDA Agricultural Research Service Nutrient Database for Standard Reference, Release 22, Washington, DC. Last accessed June 16, 2011, from www.ars.usda.gov/ba/bhnrc/ndl. Data on IDF and SDF content of fruits and vegetables, except celery, cantaloupe, and strawberries, taken from (57); data on insoluble and soluble fiber content of celery, cantaloupe, and strawberries not available in (57), so taken from (11). IDF, insoluble dietary fiber; NLEA, Nutrition Labeling and Education Act; SDF, soluble dietary fiber; TDF, total dietary fiber. 
from a USDA value for total fiber. Not surprisingly, there is much discrepancy in the fiber concentrations for fruits and vegetables.

Processing can either increase or decrease the fiber content of a fruit or vegetable. Peeling fruits or vegetables will lower the fiber content (11). A serving of grapefruit without any associated membrane contains much less fiber than a grapefruit serving with membranes ( 0.4 vs. $1.4 \mathrm{~g} /$ serving). Home cooking generally has a negligible effect on fiber content. Cooking, in general, may even increase the fiber content of a product if water is driven out in the cooking process. Baking or other heat treatments (e.g., extruding) used in food processing will also increase the fiber content of the product, either by concentrating the fiber by removal of water or producing Maillard products that are captured as fiber in gravimetric methods. Fruit juices are not devoid of fiber (Table 4).

Increasingly, research indicates that additional properties, such as viscosity and fermentability, are important characteristics in terms of the physiological benefits of fiber (Table 5 ). Viscous fibers are those that have gel-forming properties in the intestinal tract, and fermentable fibers are those that can be metabolized by colonic bacteria. In general, soluble fibers are more completely fermented and have a higher viscosity than insoluble fibers. However, not all soluble fibers are viscous (e.g., partially hydrolyzed guar gum and acacia gum) and some insoluble fibers may be well fermented.

Fibers, like starches, are made mostly of many sugar units bonded together. Unlike most starches, however, these bonds cannot be broken down by digestive enzymes and pass relatively intact into the large intestine. There, fiber can be fermented by the colonic microflora to gases such as hydrogen and carbon dioxide or it can pass through the large intestine and bind water, increasing stool weight. Although fibers are not converted to glucose, some SCFA are produced in the gut as fibers are fermented. SCFA are absorbed and can be used for energy in the body. Fibers include both "dietary fiber," the fiber naturally occurring in foods, and "functional fibers," which are isolated fibers that have a positive physiological effect. No analytical measures exist to separate dietary fiber and functional fiber, so the Nutrition Facts Label lists "Dietary Fiber," which is actually total fiber.

Table 4 TDF, IDF, and SDF in juices ${ }^{1}$

\begin{tabular}{llllcl}
\hline Food & Unit & g & TDF & IDF & SDF \\
\hline & & & & 9 & \\
Apple juice & 1 cup & 248 & 0.25 & 0.17 & 0.97 \\
Black current juice & 1 cup & 240 & 1.44 & 0.50 & 0.94 \\
Grape juice & 1 cup & 253 & 1.26 & 0.76 & 0.51 \\
Grapefruit juice & 1 cup & 247 & 0.25 & 0.05 & 0.20 \\
Apricot nectar & 1 cup & 251 & 1.51 & 0.75 & 0.75 \\
Orange juice & 1 cup & 249 & 0.75 & 0.50 & 0.25 \\
Papaya juice & 1 cup & 250 & 1.50 & 0.80 & 0.70 \\
Pineapple juice & 1 cup & 250 & 0.75 & 0.67 & 0.07 \\
Prune juice & 1 cup & 256 & 1.28 & 0.77 & 0.51 \\
\hline
\end{tabular}

${ }^{1}$ Dietary fiber concentrations for common foods from Table 1, Appendix 1 (10). IDF, insoluble dietary fiber; SDF, soluble dietary fiber; TDF, total dietary fiber.
Table 5 Classification of fibers based on 4 characteristics

\begin{tabular}{ll}
\hline Dietary fiber & Functional fiber \\
\hline Cellulose & Psyllium \\
Hemicelluloses & Fructooligosaccharides \\
Pectins & Polydextrose \\
Lignin & Insoluble fibers \\
Soluble fibers & Cellulose \\
$\beta$-Glucans & Lignin \\
Gums & Some hemicelluloses \\
Psyllium & Primary sources: wheat bran, \\
Pectin & some vegetables, some fruits, \\
Primary sources: oats, & legumes \\
barley, citrus fruits & Nonfermentable fibers \\
Fermentable fiber & Cellulose \\
Pectins & Lignin \\
$\beta$-Glucans & Primary sources: cereal fibers \\
Inulin and oligofructose & rich in cellulose, mature root \\
& vegetables \\
Primary sources: oats, barley, & \\
fruits, vegetables, grains, & \\
legumes & \\
Viscous fibers & Nonviscous fibers \\
Pectins & Cellulose \\
$\beta$-Glucans & Lignin \\
Some gums (e.g., guar gum) & Hydrolyzed guar gum \\
Psyllium & \\
\hline
\end{tabular}

\section{Dietary recommendations for fiber}

The Institute of Medicine (IOM) set an AI value for fiber of $14 \mathrm{~g}$ of fiber/1000 kcal. This value is derived from data on the relationship of fiber consumption and coronary heart disease (CHD) risk, although the IOM also considered the totality of the evidence for fiber decreasing the risk of chronic disease and other health-related conditions. Consequently, the IOM fiber recommendations are highest for populations who consume the most energy, namely young males. Fiber recommendations are lower for women and the elderly. Using this method for determining recommended fiber intake for children is problematic (e.g., intake of $19 \mathrm{~g}$ of fiber is recommended for 2-y-old children, an implausible number). The past recommendations for children were based on the age plus 5 rule (e.g., a child aged 2 y should consume $7 \mathrm{~g}$ of fiber/d) (12).

Dietary fiber is listed on the Nutrition Facts panel and 25 $\mathrm{g}$ of dietary fiber is the recommended amount in a 2000-kcal diet. Manufacturers are allowed to call a food a "good source of fiber" if it contains $10 \%$ of the recommended amount $(2.5 \mathrm{~g} /$ serving) and an "excellent source of fiber" if the food contains $20 \%$ of the recommended amount $(5 \mathrm{~g} / \mathrm{serv}-$ ing). Dietary fiber on food labels includes both dietary fiber and functional fiber.

In 2001 the IOM developed the following set of working definitions for fiber (13): dietary fiber consists of nondigestible carbohydrates and lignin that are intrinsic and intact in plants; and functional fiber consists of isolated, nondigestible carbohydrates that have beneficial physiological effects in humans.

To make recommendations for fiber intake, the IOM used prospective cohort studies that linked fiber intakes to 
lower risk of cardiovascular disease (CVD). In establishing the dietary recommended intakes, the IOM (14) recommended an AI level of $14 \mathrm{~g}$ of fiber for each $1000 \mathrm{kcal}$ of energy consumed for all individuals from $1 \mathrm{y}$ of age throughout the remainder of their lives. On the basis of median energy intakes, this equates to $25 \mathrm{~g} / \mathrm{d}$ for women and $38 \mathrm{~g} / \mathrm{d}$ for men ages $19-50 \mathrm{y}$. The AI was set at 21 and $30 \mathrm{~g} / \mathrm{d}$, respectively, for women and men aged $\geq 51 \mathrm{y}$ based on lower median energy intakes for older adults.

American women and men consume an average of only $\sim 15 \mathrm{~g}$ of fiber/d, which is far short of the suggested AI levels (9). Most commonly consumed foods are low in dietary fiber (Table 3). Generally, accepted servings of food contain from 1 to 3 grams of fiber per serving. Higher fiber contents are found in drier foods such as whole-grain cereals, legumes, and dried fruits. Other fiber sources include overthe-counter laxatives containing fiber, fiber supplements, and fiber-fortified foods. The major sources of dietary fiber in the American diets are white flour and potatoes, not because they are concentrated fiber sources but because they are widely consumed (9).

\section{Health benefits of plant intake}

Vegetarian diets have been promoted since the 18th century by men and women in search of physical and spiritual health (15). Vegetarian theorists who professed to follow the tenets of the ancient philosopher Pythagoras believed that diet should be part of an ascetic lifestyle. Vegetarianism was also symbolic of a commitment to health and social reform.

Southgate (16) described the nature and variability of human food consumption and the role of plant foods in these relationships. A wide range of plant foods is consumed, including most parts of the plant, such as fruits, seeds, leaves, roots, and tubers. Studies of hunter-gathers have shown that many plant species were collected; $>130$ species were consumed by North American Indians (17). The compositional features of plant foods are summarized (Table 6) (16). Fruits have a high water content and low levels of protein and fat. The protein is concentrated in the seeds and is resistant to digestion in the small intestine and bacterial degradation in the large intestine.

Fruits contain mostly sugars and fibers, such as pectin, that are extensively fermented in the large intestine. Certain fruits, especially apples and pears, are concentrated in fructose (18). Apples contain 6\% fructose and 3\% sucrose and pears are $6.5 \%$ fructose and $1.3 \%$ sucrose; these values would be consistent in apple and pear juices. Free fructose is poorly absorbed and would function similar to dietary fiber, escaping absorption in the small intestine while being fermented in the large intestine. This results in SCFA production, which is linked to small amounts of energy being absorbed in the colon. Additionally, it explains why apple and pear juices are used to treat constipation in children.

Fruits are also recommended as a source of vitamin $\mathrm{C}$ and potassium. Traditionally, fruits, as foodstuffs were available for a limited time and, when ripe, were sometimes difficult to collect and transport. When ripe, they have a short period of acceptability before senescence intervenes. Thus, many fruits consumed in today's world are processed, frozen, canned, or dried.

Leaves and stems are widely consumed by humans. The protein contents are higher than fruits and they contain low amounts of sugar. Leaves and stems are bulky to transport and not very stable when stored. Also, some produce secondary metabolites that have bitter or astringent properties and may produce toxic alkaloidal and other compounds such as hemoglutenens. Others produce intestinal enzyme inhibitors, such as lectins, which bind to mucosal surfaces and inhibit digestion, especially that of proteins (19).

Roots and tubers are important sources of energy as starch (Table 6). Some roots such as cassava contain toxic secondary metabolites and require soaking in water before they are safe to consume. As foodstuffs, roots, and especially tubers, can be time-consuming to collect but can be stored for long periods.

Legumes are higher in protein that other vegetables but contain toxic plant metabolites, including saponins and lectins (19). The wide use of these products was much later in evolution, once foods were cooked in water.

\section{Determinants of food choice}

Southgate (16) lists the following as factors determining food choice: 1) availability; 2) sensory preferences; 3 ) satiety; and 4) social transmission. It is generally accepted that the preference for sweet tastes is instinctive and the avoidance of bitter tastes would protect against the consumption of

Table 6 Compositional features of fruits and vegetables

\begin{tabular}{|c|c|c|c|c|}
\hline & Fruits & Legumes & Leafy vegetables & Roots and tubers \\
\hline & \multicolumn{4}{|c|}{$\mathrm{g} / 100 \mathrm{~g}$ edible matter } \\
\hline Water & $61.0-89.1$ & $74.6-80.3$ & $84.3-94.7$ & $62.3-94.6$ \\
\hline Protein & $0.5-1.1$ & $5.7-6.9$ & $0.2-3.9$ & $0.1-4.9$ \\
\hline Fat & Trace-4.4 & $1.0-15$ & $0.2-1.4$ & $0.1-0.4$ \\
\hline Sugar & $4.4-34.8$ & $1.8-3.2$ & $1.5-4.9$ & $0.5-9.5$ \\
\hline Starch & Trace-3.0 & $5.4-8.1$ & $0.1-0.8$ & $11.8-31.4$ \\
\hline Dietary fiber & $2.0-14.8$ & $4.5-4.7$ & $1.2-4.0$ & $1.1-9.5$ \\
\hline Energy, kcal & $90-646$ & $247-348$ & $65-177$ & $297-525$ \\
\hline Micronutrient & $\begin{array}{l}\text { Vitamin C, K, Mg, } \\
\text { carotenoids }\end{array}$ & $\begin{array}{l}\text { B vitamins, vitamin C, K, } \\
\text { Mg, P, Fe }\end{array}$ & $\begin{array}{l}\text { Vitamin C, folate, } \\
\text { carotenoids, Ca, Fe }\end{array}$ & $\begin{array}{l}\text { Vitamin E, carotenoids, } \\
\text { Fe, K, Ca }\end{array}$ \\
\hline Toxic constituents & $\begin{array}{l}\text { Cyanogenetic glycosides } \\
\text { in seeds }\end{array}$ & $\begin{array}{l}\text { Hemoagglutonins, lectins, } \\
\text { trypsin inhibitors }\end{array}$ & Glucosinolates & Glycoalkaloids \\
\hline
\end{tabular}


plant foods containing toxic alkaloids or other bitter plant constituents. Higher fat diets may have had advantages for satiety and concentration of energy and supported the consumption of foods such as meat or fish.

Southgate (16) discussed the selection of dietary mixtures to meet nutrition requirements. A diet of leafy plant foods would require the greatest mass of food and the amount of plant material $(>10 \mathrm{~kg})$ has too much bulk to gather and consume. The protein content of fruits is inadequate to support growth and development.

Thus, dietary guidance over time has supported the principles of moderation and variety. No food group has all the nutrients needed to support life. By consuming a variety of foods, humans avoided getting toxic doses of any component and also were successful in obtaining the required protein, vitamins, and minerals needed for growth, development, reproduction, and for sustaining life.

\section{Plant foods and health}

Historically, the consumption of certain plant foods, fruits, vegetables, and legumes was thought to prevent or curve ailments ranging from headaches to heart disease (20). Early medicine revolved around the prescription of specific foods for certain disorders. Many of these plant foods are also high in dietary fiber and phytoestrogens, so the later hypotheses often were driven by fiber, carotenoids, phytoestrogens, or other plant chemicals. Of course, determining the relationship between any dietary component and health outcomes is difficult, because diet is a complicated exposure; each day we eat a variety of foods and nutrients and linking any particular food or nutrient to a health or disease outcome is limited.

The fiber hypothesis of the 1970s was driven by stories that populations who consumed high-fiber diets had little chronic disease (9). Although these stories were often entertaining, especially accounts of the large stools associated with these healthy, nomadic people, confounding variables were not considered at the time. Scientific estimates of the intake of fiber in these populations do not exist, although it is generally accepted that the diets were high in poorly digested carbohydrates.

Current scientific thinking demands a more evidencebased review of research support. In the hierarchy of evidence, randomized controlled trails are considered the strongest support for studying dietary risk factors and disease (21). For epidemiologic studies, prospective cohort studies are deemed the strongest study designs to examine diet and disease relationships. Cross-sectional and casecontrol studies are weaker epidemiologic study designs to determine diet and disease relationships. Intervention trials are strong support for these relationships, especially because in these smaller studies, it is possible to determine the biomarkers of interest in disease prevention.

\section{Determining exposure to fiber, fruits, and vegetables in epidemiologic studies}

Dietary data are generally collected with food frequency instruments in epidemiologic studies. Estimates of total, soluble, and insoluble fiber are limited by the poor methods to measure these substances and inadequate databases. In epidemiologic studies, it is possible to count the number of servings of fruits and vegetables consumed daily if there is agreement on what counts as a serving of fruit or vegetable. Of course, fruits and vegetables vary greatly in composition. The earliest definition of a fruit was "any plant used as food," and a vegetable was a "plant, as opposed to an animal or inanimate object" (22). In the 18th century, botanical definitions were standardized and the definition of a fruit was based on its anatomy, whereas that of a vegetable was based on culinary usage. Generally, culinary custom dictates which plant foods are considered vegetables or fruits. A drawback of using a culinary definition is the misclassification of botanical fruits, e.g. squash, tomatoes, and mature beans, which despite being culinary vegetables are botanical fruits.

Within each category, other classifications can be used. For example, for vegetables, raw, cooked, canned, pickled, leafy green, and legumes are often examined. Fruits and vegetables have also been described as part of a phytochemical group, e.g., carotenoids, vitamin C, or folate (22). Other challenges of determining exposure to fruits and vegetables are that fruits are often consumed as juices and vegetables are often consumed in mixed dishes such as soups, casseroles, and stews.

Components of fruits and vegetables that have been linked to health outcomes are often placed in different categories (Table 7) (23). A wide range of compounds, beyond dietary fiber, have been linked to lower incidence of chronic diseases, especially cancer and CVD. Additionally, there are compounds in fruits and vegetables that have been linked to adverse health events (Table 7). Compounds, such as phenols, are listed in both the protective and adverse lists.

Earlier reviews that included cross-sectional studies found stronger support for the protective properties of fruit

Table 7 Protective and adverse components of fruits and vegetables linked to health outcomes

\begin{tabular}{ll}
\hline Protective & \multicolumn{1}{c}{ Adverse } \\
\hline Dietary fiber & Aflatoxin \\
Vitamin C & Pesticides \\
Vitamin E & Herbicides \\
Carotenoids & Nitrates \\
Flavonoids & Alar \\
Folic acid & Goitrogens \\
Selenium & Enzyme inhibitors \\
Dithiolthiones & Phenolic compounds \\
Glucosinolates & Saponins \\
Indoles & Inositol hexapyhosphate \\
Isothiocyanates & \\
Coumarins & \\
Phenols & \\
Protease inhibitors & \\
Plant sterols & \\
Isoflavones/lignans & \\
Saponins & \\
Inositol hexaphosphate & \\
Allium compounds & \\
Limonene & \\
\hline
\end{tabular}


and vegetable intake and disease prevention. Steinmetz and Potter (20) concluded that the scientific evidence regarding a role for vegetable and fruit consumption in cancer prevention is generally consistent and supportive of current dietary recommendations. Yet Hung et al. (24), using data from the Nurses' Health and Health Professionals prospective cohort studies, concluded that vegetables and fruit were associated with a lower risk of CVD but that the relation with cancer, overall, was null. They concluded that increased fruit and vegetable consumption was associated with a modest, although not significant reduction in the development of major chronic disease. Riboli and Norat (25) also concluded that prospective studies provide weaker evidence than do case-control studies of the association of fruit and vegetable consumption with reduced cancer risk. Smith-Warner et al. (26) examined data from 8 prospective studies of breast cancer and intake of fruits and vegetables. No association was found for total fruits, total vegetables, or total fruits and vegetables. No additional benefit was found in comparisons of the highest and lowest deciles of intake. Additionally, no associations were observed for green leafy vegetables, 8 botanical groups, and 17 specific fruits and vegetables. They concluded that fruit and vegetable consumption during adulthood is not significantly associated with reduced breast cancer risk.

Other recent studies have measured the relationships between fruit and vegetable consumption and health outcomes. Dauchet et al. (27) suggested that the evidence that fruit and vegetable consumption reduces risk of CVD remains scarce thus far. They agreed that under rigorous, controlled experimental conditions, fruit and vegetable consumption is associated with decreased blood pressure. Little experimental data exist that fruit and/or vegetable consumption affects blood lipids or other cardiovascular risk factors.

In a population-based cohort study in The Netherlands, higher consumption of fruit and vegetables, whether consumed raw or processed, was protective against CHD incidence (28). The risk of CHD incidence was 34\% lower for participants with a high intake of total fruit and vegetables ( $>475 \mathrm{~g} / \mathrm{d}$ ) compared with participants with a low total fruit and vegetable consumption $(<241 \mathrm{~g} / \mathrm{d})$.

A systematic review and meta-analysis of fruit and vegetable intake and incidence of type 2 diabetes included 6 studies, 4 of which provided separate information on the consumption of green leafy vegetables (29). No significant benefits on incidence of type 2 diabetes were found with increased consumption of vegetables, fruit, or fruit and vegetables combined. The summary estimates showed that greater intake of green leafy vegetables was associated with a $14 \%$ reduction in risk of type 2 diabetes $(P=0.01)$. Higher intakes of anthocyanins and anthocyanin-rich fruit were associated with a lower risk of type 2 diabetes when data from the Nurses' Health Study and Health Professionals follow-up cohorts were combined (30).

Dedoux et al. (31) conducted a systematic review of the relationship of fruit and vegetable intake with adiposity. They concluded that an inverse relationship between fruit and vegetable intake and adiposity among overweight adults appears weak, and this relationship among children is unclear. They suggested that whether increases in fruits and vegetables in isolation from lower energy intake or increased physical activity will result in declines or slower growth in adiposity remains unclear.

Hamidi et al. (32) systematically reviewed observational and intervention studies that investigated the effects of fruit and vegetable intake on the incidence of osteoporotic fractures, bone mineral density, and bone turnover markers in women aged $\geq 45 \mathrm{y}$. Eight studies were included. There was significant between-study heterogeneity in design, definition, and amount of fruit and vegetable intake, outcomes, analyses, and reporting of results. They concluded that based on the limited evidence, the benefits of fruit and vegetable intake on bone health remain unclear.

Fruit and vegetable consumption and prospective weight change was determined in participants of the European Prospective investigation into Cancer and Nutrition study. The investigators determined the association between baseline consumption and fruit and vegetables and weight change in participants from 10 European countries (33). Baseline fruit and vegetable intakes were not associated with overall weight change.

The study of vegetables and fruits on human health is complicated by many factors, including their large variety globally, varying dietary patterns, different effects for vegetables compared with fruits, and interactions with other dietary components. However, most Americans in all age-sex groups consume substantially fewer vegetables and fruits than is recommended.

\section{What Is a serving of fruit or vegetable?}

What counts as a serving of fruit or vegetable continues to be debated. Although this seems like a simple exercise, government officials and nutritionists do not agree on what counts as a serving of a fruit or vegetable. During the Reagan era, the idea that pickles and ketchup counted as vegetable servings made nutrition policy makers the laughingstock of late night TV hosts. More recent debates on whether French fries or tomato paste on pizza count as vegetables in school lunch have added to the frenzy. Published studies on 3 methods for counting fruits and vegetables in 4th grade students found that different counting methods yielded significantly different tallies of fruit and vegetable intake (34).

Government agency recommendations for fruits and vegetables also vary (Table 1). There are many disagreements on what counts, especially for juices, starchy vegetables, and legumes. Most of these divisions are based more on philosophy rather than nutrient content. Ruxton et al. (35) considered whether the protective benefits of fruit and vegetables were dependent upon constituents lacking in juices (fiber) and whether juices affect disease risk when considered separately from fruits and vegetables. They concluded that the view that fruit and vegetable juices are nutritionally inferior to fruits and vegetables in relation to chronic disease risk reduction is unjustified. 
Oude Griep et al. (28) measured the association of fruit and vegetable consumption with $10-y$ CHD incidence in a population-based study in The Netherlands and whether processing had any affect on these associations. They found that higher consumption of fruit and vegetables, whether consumed raw or processed, protected against $\mathrm{CHD}$ incidence.

\section{Health benefits of specific fruits and vegetables}

Some fruits and vegetables have been studied separately either in prospective cohort studies or randomized controlled trials. Typically, these fruits or vegetables are of interest because of their phytochemical contents, including polyphenols, phytoestrogens, and antioxidants. Studies in berries were summarized by Basu et al. (36). Intervention studies found mixed results, with only 2 of 20 trials showing decreases in systolic blood pressure with berry consumption. Results with inflammation markers were equally mixed. Cranberries have been studied more extensively, especially for their role in prevention and treatment of urinary tract infections (37).

Grapes have also been extensively studied, mostly in response to the French paradox, the finding that the French diet is high in fat but CVD incidence is low. Consumption of red wine has been proposed as a protective mechanism, because grapes are high in antioxidants, namely flavonoids (38). Grape polyphenols can reduce atherosclerosis by inhibiting LDL oxidation and platelet aggregation, improving endothelial function, lowering blood pressure, reducing inflammation, and activating novel proteins that prevent cell senescence (39). Despite the promise of grapes and disease prevention, little epidemiologic evidence supports a unique role for grapes in disease prevention or health. A review of apples and apple components and their relationship to human health also suggested many potential mechanisms by which apples could affect health (40).

Potatoes are a staple vegetable in many parts of the world. Unlike leafy green vegetables, potatoes are rich in starch and provide protein of high biological value (41). Potatoes are rich in vitamin $\mathrm{C}$ and potassium and provide dietary fiber, especially if the skins are consumed. Few prospective studies have examined the relationship between potato consumption and health. Some data from the Nurses' Health Study suggest that potatoes and French fries are linked to risk of type 2 diabetes in women (42).

Besides looking at consumption of fruits or vegetables as the endpoint, some studies have examined intake of flavonoids and cardiovascular risk. A recent meta-analysis of randomized controlled trials in this area was conducted (43). For most of the flavonoids, there was insufficient evidence to draw conclusions about efficacy. Most of the published studies were with either soy or cocoa. The authors suggest that future studies need to be conducted in more flavonoid-rich foods and be of sufficient duration to measure changes in biomarkers. Chong et al. (44) examined the relationship between fruit polyphenols and CVD risk, particularly human intervention studies that examined platelet function, blood pressure, vascular function, and blood lipids. Not surprisingly, the results were limited and often there was inconsistency in study designs. They noted that the current support to consume a variety of fruits and vegetables daily is consistent with the lack of convincing data that any one fruit or vegetable is of particular importance.

Intake data on phytonutrients concentrated in fruits and vegetables are limited. Murphy et al. (45) estimated the usual intake of 9 individual phytonutrients in Americans consuming the recommended levels of fruits and vegetables. The energy-adjusted intakes of all phytonutrients other than ellagic acid were higher among those meeting the dietary recommendations for fruit and vegetable intakes in the NHANES 2003-2006 survey. For 5 of the 9 phytonutrients ( $\alpha$-carotene, $\beta$-cryptoxanthin, lycopene, hesperetin, and ellagic acid), a single food accounted for $\geq 64 \%$ of the total intake of the phytonutrient.

\section{Do fruits and vegetables affect satiety?}

Satiation and satiety are controlled by factors that begin when a food is consumed and continue as it enters the gastrointestinal tract and is digested and absorbed (46). As food moves down the digestive tract, signals are sent to the brain and gut hormones are produced that affect energy balance in a variety of ways, including slowing gastric emptying, acting as neurotransmitters, and reducing gastrointestinal secretions. These effects are proposed to influence satiety. The terms satiety and satiation are often used differently in the literature and many methods to measure each exist.

The most common study design for satiety studies uses a test preload in which variables of interest are carefully controlled. Generally, participants rate aspects of their appetite sensations, such as fullness or hunger at intervals and then, after a predetermined time interval, a test meal at which energy intake is measured. Longer term studies typically provide foods or drinks of a known composition to be consumed ad libitum and use measures of energy intake and/or appetite ratings as indicators of satiety. Satiety tests are often conducted with liquids where differences in macronutrient content are more easily formulated. However, it is difficult to formulate and blind products that vary greatly in the content of fiber, protein, fat, and carbohydrate.

The measurement of satiety is complicated, because many internal signals also influence appetite, such as bodyweight, age, sex, habitual diet, exercise, and dietary restraint. These acute studies are typically done in laboratory settings where variables can be controlled. Visual analogue scales are usually used to monitor hunger, fullness, and motivation to eat. Studying the effects of one variable in food or drink while keeping others constant is inherently difficult, especially if researchers do not want the differences to be obvious to participants. Adding fiber to foods decreases energy density and often palatability, both of which can affect satiety (47).

The carbohydrate content of foods and drinks is diverse and includes digestible carbohydrates and fiber. In the 1950s, the glucostatic theory of appetite regulation was developed by Mayer (48), who hypothesized that blood glucose levels 
determined appetite, initiating energy intake when low and causing satiety when increased. Glucose levels do affect satiety and thus the intake of energy as carbohydrate must be controlled and balanced in satiety studies.

Fiber includes a wide range of compounds and although fiber generally affects satiety, not all fibers are equally effective in changing satiety (47). Generally, whole foods that naturally contain fiber are satiating. Flood-Obbagy and Rolls (49) compared the effect of fruit in different forms on energy intake and satiety at a meal. The results showed that eating an apple reduced lunch energy intake by $15 \%$ compared with control. Fullness ratings significantly differed after preload consumption, with apple being the most satiating, followed by applesauce, then apple juice, then the control food. The addition of a pectin fiber to the apple juice did not alter satiety.

Other fibers added to drinks do change satiety. Pelkman et al. (50) added low doses of a gelling pectin-alginate fiber to drinks and measured satiety. The drinks were consumed twice per day for $7 \mathrm{~d}$ and energy intake at the evening meal was recorded. The 2.8-g dose of pectin alginate caused a decrease of $10 \%$ in energy intake at the evening meal.

A few studies have been published on the effects of fruits or vegetables and satiety and glucose or insulin response. Haber et al. (51) conducted a small study $(n=10)$ on the depletion and disruption of dietary fiber and effects on satiety, plasma glucose, and serum insulin. When they equalized the rate of ingestion, apple juice was significantly less satisfying than apple puree and puree than apples. Plasma glucose rose to similar levels after all 3 treatments. Serum insulin rose to higher levels after juice and puree than after apples. They suggested that the removal of fiber from food and also its physical disruption can result in faster and easier ingestion, decreased satiety, and disturbed glucose homeostasis. Bolton et al. (52) compared the responses of whole oranges and whole grapes with juices. The results for oranges were similar to those reported for apples. In contrast, for grapes, the insulin response to the whole fruit was greater than with the grape juice. The authors concluded that insulin and glucose responses depend on both the glucose and fiber contents of the fruit.

The effects of different vegetables, carrots, peas, Brussels sprouts and spinach, on glucose homeostasis and satiety was measured in typical Swedish lunch test meals in 10 participants (53). The added vegetables contained $4.4 \mathrm{~g}$ of dietary fiber. Postprandial blood glucose, plasma insulin, and C-peptide levels were measured at regular intervals until 210 min after consumption. The meal with spinach elicited significantly lower insulin and C-peptide responses than the control meal, but no significant differences in glucose response or satiety were observed. The other vegetables showed no significant effects on glucose and hormonal responses or satiety.

The bioavailability of compounds in fruits and vegetables may be altered by the physical property of the fruit or vegetables, although these interactions are difficult to study in the whole animals (54). Properties beyond fiber alter physiological properties such as gastric emptying. Willis et al. (55) fed 2 breakfasts, both containing $10 \mathrm{~g}$ of dietary fiber and $410 \mathrm{kcal}$. The breakfasts differed only in that one was liquid (a fiber-enhanced juice) and the other was solid (oatmeal, blueberries, and apples). Gastric emptying time, as measured by a Smartpill, was $1 \mathrm{~h}$ longer with the solid breakfast. The solid meal also decreased hunger more than a liquid meal with added fiber.

Satiety was also affected by the expected changes in a recent study by Brunstrom et al. (56). In this study, participants were shown the ingredients of a fruit smoothie. One-half were shown a small portion of fruit and one-half were shown a large portion. Participants then assessed the expected satiety of the smoothie and provided appetite ratings before and for $3 \mathrm{~h}$ after its consumption. The expected satiety was significantly higher in the "large portion" condition, although both treatments were the same. The authors concluded that beliefs and expectations can have marked effects on satiety and can persist into the inter-meal interval.

\section{Conclusions}

Epidemiologic studies support that dietary fiber is linked to less CVD and probably has a role in obesity prevention. Because fruit and vegetable intake is so low in U.S. studies, it is not possible to isolate the effects of any particular fruit or vegetable fiber or category of fruits or vegetable (fresh, processed, starchy, etc.) on health outcomes in these studies. Fiber is most concentrated in dried fruits and cooked vegetables, just because water is removed and fiber concentrated.

Fruits, vegetables, and legumes vary widely in nutrient content so should not be expected to have similar physiological effects. Although dietary guidance is supportive of a more vegetarian eating pattern, including increased servings of fruits and vegetables, the scientific support for these recommendations is mixed in an evidence-based review. Prospective cohort studies find weak support for the protectiveness of fruits and vegetables against chronic diseases, yet intake of fruits and vegetables in U.S. cohorts is low. Additionally, few randomized controlled trials have been published on the addition of fruits and vegetables to the diet and changes in biomarkers or health status. Nutrients in fruits and vegetables, such as dietary fiber, vitamins, minerals, and phytochemicals, including polyphenols, all provide support for the biological plausibility that fruits and vegetables play a role in health.

Food form may play a role in satiety. Fiber added to drinks appears less effective than whole fruits or vegetables in enhancing satiety. Limited studies suggest that whole-fiber foods may slow gastric emptying compared with liquid foods with added fiber.

Both epidemiologic and experimental fiber studies are linked to improved health status. Fiber is an accepted nutrient and a short-fall nutrient, so public health messages to increase fiber consumption are warranted. Intakes of fruits and vegetables are also widely promoted, both for the content of fiber and other nutrients. Whenever possible, the entire fruit or vegetable, i.e., peel and membrane, should be consumed to increase fiber consumption. Satiety studies 
also suggest that closer to "whole" may have advantages, although the mechanisms for this effectiveness are not known. Fiber is definitely an active component of fruits and vegetables and a reason to continue to support their consumption.

\section{Acknowledgments}

Both authors read and approved the final manuscript.

\section{Literature Cited}

1. Canada's Food Guide. Ottawa: Health Canada; 2007.

2. United Kingdom Eatwell Plate, Food Standards Agency; 2007 [last accessed June 12, 2011]. Available from: eatwell.gov.uk.

3. USDA and U.S. Department of Health and Human Services. Dietary Guidelines for Americans, 2010. 7th ed. Washington, DC: U.S. Government Printing Office; 2010.

4. Hornick BA, Weiss L. Comparative nutrient analysis of commonly consumed vegetables. Nutr Today. 2011;46:130-7.

5. Song W, Derito CM, Liu K, He X, Dong M, Liu RH. Cellular antioxidant activity of common vegetables. J Agric Food Chem. 2010;58:6621-9.

6. Marriott BP, Olsho L, Hadden L, Connor P. Intake of added sugars and selected nutrients in the United States, National Health and Nutrition Examination Survey (NHANES) 2003-2006. Crit Rev Food Sci Nutr. 2010;50:228-58.

7. Slavin JL. Dietary fiber: classification, chemical analyses, and food sources. J Am Diet Assoc. 1987;87:1164-71.

8. Lanza E, Butrum RR. A critical review of food fiber analysis and data. J Am Diet Assoc. 1986;186:732-43.

9. Slavin JL. Position of the American Dietetic Association: health implications of dietary fiber. J Am Diet Assoc. 2008;108:1716-31.

10. Schakel SF, Sievert VA, Buzzard IM. Dietary fiber values for common foods. Appendix I. In: Spiller GA, editor. CRC handbook of dietary fiber in human nutrition. 2nd ed. Boca Raton (FL): CRC Press; 1993. p. 595-605.

11. Marlett JA, Cheung T. Database and quick methods of assessing typical dietary fiber intakes using data for 228 commonly consumed foods. J Am Diet Assoc. 1997;97:1139-48, 1151.

12. Kranz S, Brauchla M, Slavin JL, Miller KB. What do we know about dietary fiber intake in children and health? The effects of fiber intake on constipation, obesity, and diabetes in children. Adv Nutr. 2012;3:47-53.

13. Institute of Medicine. Food and Nutrition Board, Dietary Reference Intakes proposed definition of dietary fiber, a report of the Panel on the Definition of Dietary Fiber and the Standing Committee on the Scientific Evaluation of DRIs. Washington, DC: National Academies Press; 2001.

14. Institute of Medicine. Food and Nutrition Board, Dietary Reference Intakes: energy, carbohydrates, fiber, fat, fatty acids, cholesterol, protein, and amino acids. Washington, DC: National Academies Press; 2002.

15. Roe DA. History of promotion of vegetable cereal diets. J Nutr. 1986; 116:1355-63.

16. Southgate DAT. Nature and variability of human food consumption. Philos Trans R Soc Lond B Biol Sci. 1991;334:281-8.

17. Gonzales NL. Changing patterns of North American Indians. In: Moore WM, Siberberg MM, Read MS, editors. Nutrition, growth and development of North American Indian children. Publication No. NIH 72-26. Washington, DC: US Department of Health and Welfare; 1969. p.15-33.

18. Southgate DAT, Paul AA, Dean AC, Christie AA. Free sugars in foods. J Hum Nutr. 1978;32:335-47.

19. Liener IE. Toxic constituents of plant foods. New York: Academic Press; 1989.

20. Steinmetz KA, Potter JD. Vegetables, fruit, and cancer prevention: a review. J Am Diet Assoc. 1996;96:1027-39.

21. Blumberg J, Heaney RP, Huncharek M, Scholl T, Stampfer M, Vieth R, Weaver CM, Zeisel SH. Evidence-based criteria in the nutritional context. Nutr Rev. 2010;68:478-84.

22. Smith SA, Campbell DR, Elmer PJ, Martini MC, Slavin JL, Potter JD. The University of Minnesota Cancer Prevention Research Unit vegetable and fruit classification scheme (United States). Cancer Causes Control. 1995;6:292-302.

23. Steinmetz KA, Potter JD. Vegetables, fruit, and cancer. II. Mechanisms. Cancer Causes Control. 1991;2:427-42.

24. Hung HC, Joshipura KJ, Jiang R, Hu FB, Hunter D, Smith-Warner SA, Colditz GA, Rosner B, Spiedelman D, Willett WC. Fruit and vegetable intake and risk of major chronic disease. J Natl Cancer Inst. 2004;96: 1577-84.

25. Riboli E, Horel T. Epidemiologic evidence of the protective effect of fruit and vegetables on cancer risk. Am J Clin Nutr. 2003;78 Suppl 3:S559-69.

26. Smith-Warner SA, Spiegelman D, Yaun SS, Adami HO, Beeson WL, van den Brandt PA, Folson AR, Fraser GE, Freudenheim JL, Goldhobohm RA, et al. Intake of fruits and vegetables and risk of breast cancer: a pooled analysis of cohort studies. JAMA. 2001;285:769-76.

27. Dauchet L, Amouyel P, Hercberg S, Dallongeville J. Fruit and vegetable consumption and risk of coronary heart disease: a meta-analysis of cohort studies. J Nutr. 2006;136:2588-93.

28. Oude Griep LM, Gelejinse JM, Kronhout D, Ocke MC, Verschuern WM. Raw and processed fruit and vegetable consumption and 10year coronary heart disease incidence in a population-based cohort study in the Netherlands. PLoS ONE. 2010;5:e13609.

29. Carter P, Gray LJ, Troughton J, Khunti K, Davies MJ. Fruit and vegetable intake and incidence of type 2 diabetes mellitus: systematic review and meta-analysis. BMJ. 2010;18:341:c4229.

30. Wedick NM, Pan A, Cassidy A, Rimm EB, Sampson L, Rosner B, Willett W, Hu FB, Sun Q, van Dam RM. Dietary flavonoid intakes and risk of type 2 diabetes in US men and women. Am J Clin Nutr. 2012;95:925-33.

31. Ledoux TA, Hingle MD, Baranowski T. Relationship of fruit and vegetable intake with adiposity: a systematic review. Obes Rev. 2011;12: e143-50.

32. Hamidi M, Boucher BA, Cheung AM, Beyene J, Shah PS. Fruit and vegetable intake and bone health in women aged 45 years and over: a systematic review. Osteoporos Int. 2011;22:1681-93.

33. Vergnaud AC, Norat T, Romaguera D, Mouw T, May AM, Romieu I, Freisling H, Slimani N, Boutron-Ruault MC, Clavel-Chapelon F, et al. Fruit and vegetable consumption and prospective weight change in participants of the European Prospective Investigation into Cancer and Nutrition: Physical Activity, Nutrition, Alcohol, Cessation of Smoking, Eating Out of Home, and Obesity study. Am J Clin Nutr. 2012;95:184-93.

34. Eldridge AL, Smith-Warner SA, Lytle LA, Murray DM. Comparison of 3 methods for counting fruits and vegetables for fourth-grade students in the Minnesota 5 A Day Power Plus Program. J Am Diet Assoc. 1998;98:777-82.

35. Ruxton $\mathrm{CH}$, Gardner EJ, Walker D. Can pure fruit and vegetable juices protect against cancer and cardiovascular disease too? A review of the evidence. Int J Food Sci Nutr. 2006;57:249-72.

36. Basu A, Rhone M, Lyons T. Berries: emerging impact on cardiovascular health. Nutr Rev. 2010;68:168-77.

37. Côté J, Caillet S, Doyon G, Sylvain JF, Lacroix M. Bioactive compounds in cranberries and their biological properties. Crit Rev Food Sci Nutr. 2010;50:666-79.

38. Vislocky LM, Fernandez ML. Biomedical effects of grape products. Nutr Rev. 2010;68:656-70.

39. Dohadwala MM, Vita JA. Grapes and cardiovascular disease. J Nutr. 2009;139:S1788-93.

40. Hyson DA. A comprehensive review of apples and apple components and their relationship to human health. Adv Nutr. 2011;2:408-20.

41. Camire ME, Kubow S, Donnelly DJ. Potatoes and human health. Crit Rev Food Sci Nutr. 2009;49:823-40.

42. Halton TL, Willett WC, Liu S, Manson JE, Stampfer MJ, Hu FB. Potato and French fry consumption and risk of type 2 diabetes in women. Am J Clin Nutr. 2006;83:284-90.

43. Hooper L, Kroon PA, Rimm EB, Cohn JS, Harvey I, Le Cornu KA, Ryder JJ, Hall WL, Cassidy A. Flavonoids, flavonoid-rich foods, and cardiovascular risk: a meta-analysis of randomized controlled trials. Am J Clin Nutr. 2008;88:38-50. 
44. Chong MFF, Macdonald R, Lovegrove JA. Fruit polyphenols and CVD risk: a review of human intervention studies. Br J Nutr. 2010;104:S28-39.

45. Murphy MM, Barraj LM, Herman D, Bi X, Cheatham R, Randolph RK. Phytonutrient intake by adults in the United States in relation to fruit and vegetable consumption. J Am Diet Assoc. Epub 2011 Nov 9.

46. Benelam B. Satiation, satiety and their effects on eating behaviour. Nutr Bull. 2009;34:126-73.

47. Slavin J, Green H. Dietary fibre and satiety. Nutr Bull. 2007;32 Suppl 1: 32-42.

48. Mayer J. Glucostatic mechanism of regulation of food intake. N Engl J Med. 1953;249:13-6.

49. Flood-Obbagy JE, Rolls BJ. The effect of fruit in different forms on energy intake and satiety at a meal. Appetite. 2009;52:416-22.

50. Pelkman CI, Navia JL, Miller AE, Pohle RJ. Novel calcium-gelled pectin beverage reduced energy intake in non-reducing overweight and obese women. Am J Clin Nutr. 2007;86:1595-602.

51. Haber GB, Heaton KW, Murphy D, Burroughs LF. Depletion and disruption of dietary fibre: effects on satiety, plasma glucose and serum insulin. Lancet. 1977;2:679-82.
52. Bolton RP, Heaton KW, Burroughs LF. The role of dietary fiber in satiety, glucose, and insulin: studies with fruit and fruit juice. Am J Clin Nutr. 1981;34:211-7.

53. Gustafsson K, Asp NG, Hagander B, Nyman M. Effects of different vegetables in mixed meals on glucose homeostasis and satiety. Eur J Clin Nutr. 1993;47:192-200.

54. Palafox-Carlos H, Ayala-Zavala JH, Gonzalez-Aquilar CA. The role of dietary fiber in the bioaccessibility and bioavailability of fruit and vegetable antioxidants. J Food Sci. 2011;76:R6.

55. Willis HJ, Thomas W, Willis DJ, Slavin JL. Feasibility of measuring gastric emptying time, with a wireless motility device, after subjects consume fiber-matched liquid and solid breakfasts. Appetite. 2011;57: 38-44.

56. Brunstrom JM, Brown S, Hinton EC, Rogers PJ, Fay SH. 'Expected satiety' changes hunger and fullness in the inter-meal interval. Appetite. 2011;56:310-5.

57. Li BW, Andrews KW, Pehrsson PR. Individual sugars, soluble, and insoluble dietary fiber contents of 70 high consumption foods. J Food Compost Anal. 2002;15:715-23. 